\title{
Indagações Sobre os Fundamentos da Linguagem
}

\author{
Ignacio Assis Silva
}

1. O Dicionário de Semiótica I, de Greimas e Courtés, acostumou-nos a pensar na figurativização como um problema de semiótica discursiva. Partindo de uma formulação genérica do conceito como as mil maneiras de contar como um sujeito disjunto de seu objeto-valor passa a conjunto ou vice-versa, os Autores acrescentam que a fïgurativizaçào:

- transforma processos em ações,

- confere contornos figurativos ao sujeito que, com isso, sc torna uin ator (sofre ancoragem espacio-temporal).

Isso se faz em dois patamares:

- o da figuração,

- o da iconização

(Ver Greimas e Courtés, s/d:185-187)

O Dicionário de Semiótica II (Greimas c Courtés, 1986), no verbete "figuratividade", vai insistirna diferença entre figuratividade efigurativizaçāo. Distinguir-se-ão, assim, procedimentos discursivos que produzem isotopias figurativas, cuja tarefa mais importante "não é suscitar impressões referenciais, mas, perdendo todo contato com a referenciação, estruturar de maneira bastante abstrata a significação " (1986:91), daqueles procedimentos discursivos que explicam como as figuras, entramando-se, produzem oefeito de sentido realidade. Os primeiros constituem uma trama figurativa elementar (un estenograma) que estrutura o nivel profundo do discurso. São estudlados pela semântica fundamental da Gramática Profunda. Já os segundos constituem a figura- 
tivização propriamente dita e serão objeto de estudo da Gramática Discursiva (Semântica).

É à luz dessas distinções que procuraremos repensar a questão da metamorfose como um lugar privilegiado para as indagações sobre os fundamentos da linguagem.

\section{Três exemplos típicos de metamorfoses}

2.1. Da plenitude figurativa ao mínimo figurativo: “As metamorfoses de um touro", de Picasso.

O texto picassiano mostra-nos, de início, um touro soberbo, roliço, bojudo, que, vai, aos poucos, transformando-se até restar apenas um tourolinha, um touro-estenograma, um touro-fora-de-todo-e-qualquer-contexto.

Metamorfose anti-ovidiana, o texto de Picasso suprime, tira, em vez de acrescentar. Uma verdadeira caminhada do "touro" à "tauridade" convicentemente acentuada pelas chamativas expressões que balizam o texto-comentário de Hélène Parmelin:

- tirar em vez de por,

- decompor o touro,

- sobrar menos touro,

- parecer uma formiga,

- suprimir, suprimir,

- terminar por onde normalmente deveria começar,

- pinturas que parecem não ter nada, mas têm tudo,

- touro fora de todo e qualquer contexto

2.2. Do mínimo figurativo à plenitude figurativa: "A transformação de Níobe cm pedra", de Ovídio:

"Tendo perdido toda sua familia, Níobe cai sentada no meio dos corpos inanimados do marido e de seus filhos e filhas, enrigescida pela dor. $O$ vento nāo agita sequer um fio de cabelo; nem uma gota de sangue colore suas faces; os olhos quedam imóveis no semblante 

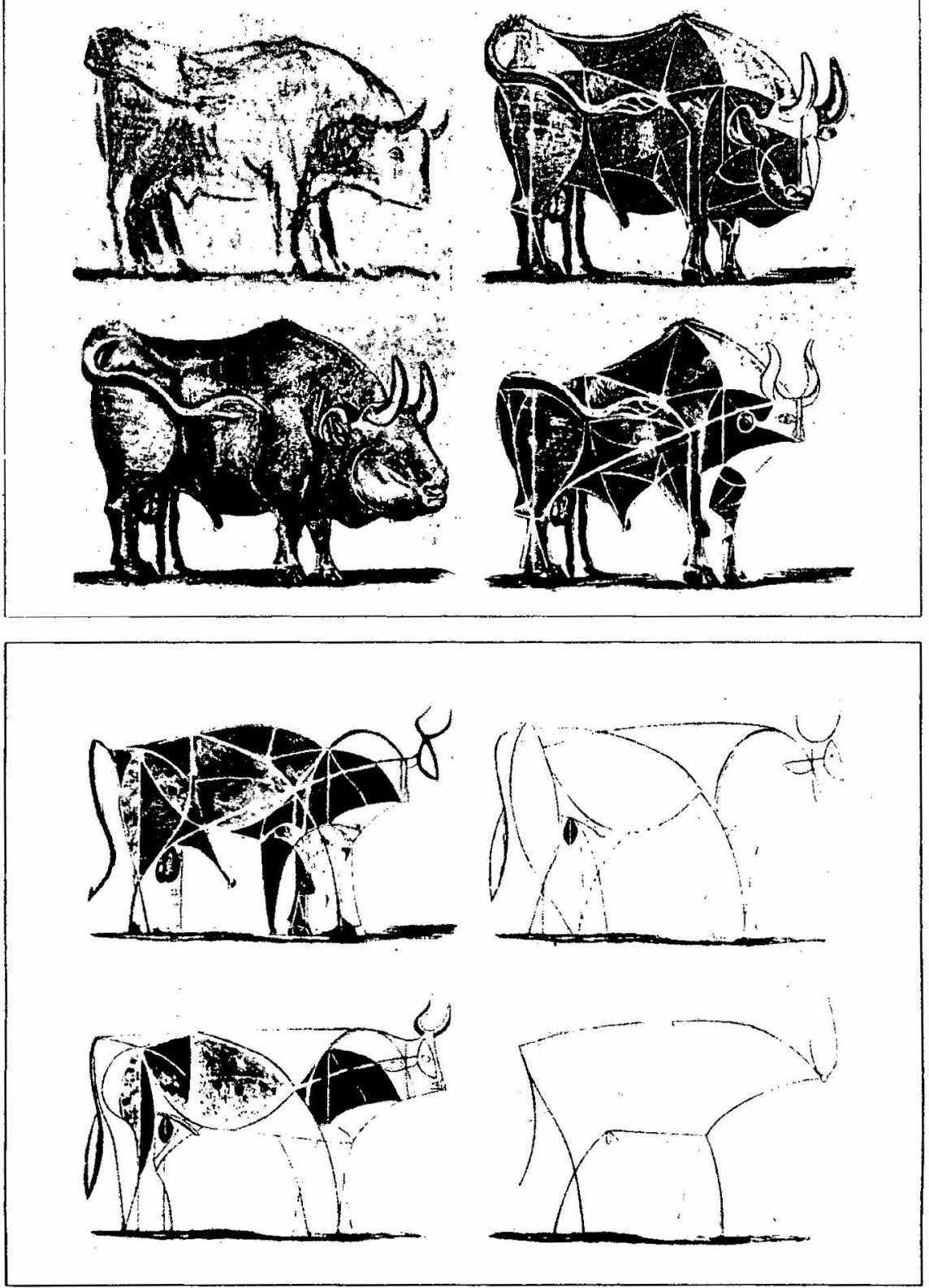

As Metamortoses de um Touro - Pablo Picasso . 
desolado; nenhum traço de vida anima o seu rosto; a própria língua se congela no interior (da boca) junto ao duro palato; cessa todo movimento em suas veias; o pescoço não pode mais dobrar-se; os braços não podem mais mover-se, nem os pés conseguem avançar; até nas suas entranhas, tudo é pedra. Mas Níobe chora". (Metamorphoses I: 303-312).

Ao contrário do que vimos acontecer no texto picassiano, Ovídio destaca, de início, um traço que individua o objeto, estabelecendo assim um arcabouço figurativo elementar, como a rigidez que invade o corpo de Níobe e, a seguir, vai acrescentando traços que denotam qualidades físicas e espaciais, pelas quais se exprimem os sintomas de transformaçāo:

- o vento que nāo move os cabelos,

- a cor das faces que desaparece,

- os olhos que se imobilizam,

- o pescoço que não se dobra,

- as māos incrtes,

- os pés que nāo avançam,

- etc.

Em seu artigo "Alcuni tratti strutturali delle Metamorfosi di Ovidio", J. Scegelov (1962: 113) mostra que a metamorfose ovidiana está embasada no trabalho com adjetivos que denotam qualjdades como a curvatura, o vazio, o estado líquido ou sólido, o estado de tensão do objeto, e assim por diante. Quando escolhe um adjetivo com que isola a qualidade de um objeto, esse adjetivo já contém a indicação do caminho que pode levá-lo a transformar-se em outro. Assim, quando se diz de uma pedra que é "dura" e "informe", isso já sugere a existência de outros objetos que săo "moles" e "dotados de forma". $\mathrm{O}$ efeito da metamorfose reside, todo, no fato de que uma coisa é diferente da outra, mas sendo comensurável a ela, presta-se facilmente à transformação.

2.3. Conflitos actanciais e temáticos: "A metamorfose de Gregório Samsa", de Kafka.

- Das mudanças no corpo: 
“Certa manhã, quando Gregório Samsa acordou, após um sono intranquilo, achou-se em sua cama convertido em monstruoso inseto. Estava deitado sobre a dura carapaça de suas costas e, ao erguer um pouco a cabeça, viu a figura convexa de seu ventre escuro, sulcado por pronunciadas ondulações, cuja proeminências a colcha mal podia aguentar, pois estava visivelmente a ponto de escorregar atéao solo. Inúmeras patas, lamentavelmente esquálidas em comparação com a grossura comum de suas pernas, ofereciam a seus olhos o espetáculo de uma agitação sem consistência". (Kafka, 1976: 9),

- Às mudanças nas relações actoriais:

O texto kafkiano enfatiza os conflitos actanciais (mudanças na estrutura modal dos Actantes) e temáticos (mudanças na estrutura dos papéis temáticos desencadeadas pelas transformações figurativas. Por exemplo: provedor/provido; protetor/protegido; perseguidor/perseguido, etc.).

\section{Metamorfose e pensamento mítico: a adesão ao aspecto concreto e particular das coisas}

Ernst Cassirer (1945: 126) diz que "Si existe algún rasgo característico y sobresaliente del mundo mítico, alguna ley que lo gobierna, es ésta de la metamorfosis", para acrescentar, na página seguinte, que "Lo que caracteriza a la mentalidad primitiva no es su lógica sino su sentimiento general dela vida".

É sob esse prisma que desejamos focalizar as metamorfoses picassiana e ovidiana. Ambas revelam a mesma orientação para os aspectos concretos. Mutatis mutandis, a caminhada picassiana assemelha-se ao percurso desenvolvido por Greimas (1966: 43 e seg.) na análise sêmica de "cabeça". Picasso chega ao "touro-linha", Greimas à "cabeça-extremidade superativa". Como Ovídio, isolan traços que denotam qualidades físicas e espaciais, chegando ao que se poderia chamar de substrato figurativo ou tramafigurativa elementar do objeto. A associação aqui é inevitável dessa concepção às percepções visuais esquematizadas que, segundo Raymound Ruyer, permitem às aves saber de uma outra que se aproxima se ć inimiga ou amiga, com base nas oposições:

pescoşo comprido / cauda curta

vs.

pescoşo curto $/$ cauda comprida

(Ct.Greimas 1966: 64) 
A mesma orientação para o concreto é sugestivamente ilustrada pelo papel sagrado do rei na concepção indo-européia:

"Em rex - diz Benveniste (1969:9) - importa ver menos o soberano do que aquele que traca a linha, ocaminho a seguir que encarna ao mesmo tempo o que é direito: a noçāo concreta enunciada pela raiz ${ }^{*}$ reg-está muito mais viva em rex, na origem, do que nós pensamos" (grifos nossos).

Ainda a respeito dessa adesão ao concreto que resulta do sentimento geral da vida, vemos como fontes ricas de inspiração as consideraçōes de Cassirer (1972: 113) sobre o princípio de equivalência que leva a linguagem a tratar como iguais contcúdos que, do ponto de vista da reflexão analítica e científica, se nos afiguram altamente diversificados. Depois de citar Preuss (Die geistige Kultur der Naturvolker, Leipzig, 1914), segundo o qual o indio cora, de um modo que, à primeira vista nos parece inteiramente absurdo, coloca as mariposas entre os pássaros, Cassirer lembra que nossas próprias línguas atuais continuam criando, sem parar, semelhantes coordenaçōes, que contradizem nossos conceitos empíricos e científicos das espécies e classes, como acontece, por exemplo, nas línguas germânicas, onde a mariposa é costumeiramente chamada de "pássaro manteiga" ou "mosca-manteiga" (Buttervogel e Butterfliege em alemão; botervlieg, em holandês; butterfly, em inglês. (Cf. Cassirer 1972: 113). Tais denominações realçam como decisivo e essencial o momento de "vôo", o mesmo momento que o indio cora isola na denominaçāo da mariposa.

O "touro-linha" de Picasso, a "cabeça-extremidade-primeira”, da análise greimasiana, a qualidade física e espacial isolada por Ovídio, as percepções visuais esquematizadas das aves de Ruyer, a "mariposa-vôo", do índio cora ou o pássaro-vôo da escultura de Brancusi (1), todos mostram que o substrato figurativo do objeto é feito de figuras do conteúdo que correspondem a figuras do plano de expressāo de semióticas não linguísticas, as quais enformam a macrossemiótica do Mundo Natural (2). Sảotraçosexteroceptivos, cosmológicos engendrados pela semiotização de traços da relação do homem com o mundo natural. Desse ponto de vista, representam, como quer Greimas (1966: 65), a contribuição do mundo exterior ao nascimento do sentido. Entendendo como enérgeia e não como érgon a relação que une as grandes semióticas em que se articula a produção de sentido (a Lingua Natural e o Mundo Natural), o programa ovidiano In noua mutatas dicere formas corpora (Met.I: 1-2) surge como um empreendimento metalinguístico (dicere) de explicaçāo do sentido do homem no mundo: 


\section{Língua Natural Enérgeia Mundo Natural}

traços conceptuais,

noológicos

In noua corpora $<-$ mutatas $<-$ formas

traços perceptuais,

cosmológicos

Metamorfose

cosmologicos

\section{Ut pictura poesis (Horácio): A figuratividade como um patamar comum a diferentes semióticas}

Heródoto disse que Homero e Hesíodo deram aos deuses gregos seus nomes e esboçaram suas figuras. Cassier - que nos dá essa informação--, acrescenta: "La obra comenzada por la poesía griega fue completada por la escultura: nos es dificil pensar en el Zeus olimpico sin representárnoslo en la forma que le prestó Fidias". (1945: 150). A arte dos fazedores de imagens (escultura e pintura) e a arte da palavra (poesia) surgiam já para os gregos como dotadas de um embasamento comum, não obstante fossem postas numa relação de complementaridade: a poesia esboçava as figuras dos deuses, o scu perfil, enquanto a pintura e sobretudo a escultura lhes davam a plenitude figurativa. É que os fazedores de imagem gregos estavam muito mais preocupados com o eiconopoiein, com a figurativização, do que com a figuratividade.

Hoje, ao retomarem a problemática lapidarmente sintetizada na fórmula horaciana, os semioticistas, de modo especial os visualistas, concentram sua atenção na figuratividade, que concebem como um patamar comum às diferentes linguagens, situável na camada fundamental do percurso gerativo: “As isotopias figurativas podem não apenas suscitar impressões referenciais, mas, perdendo todo contato com a referenciação, podem igualmente estruturar de maneira bastante abstrata a significação $e$ organizar o nivel profundo do discurso, constituindo aí uma linguagem figurativade tipo metassemiótico " (J.M. Floch, in Greimas e Courtés 1986: 91). Vemos assim as indagaçōes do semioticista convergirem para um tipo de preocupação semelhante àquela que marcou os principais momentos da História da Arte Moderna. Rcalizam um percurso como a da metamorfose picassiana que vai do figurativo, tal como se 


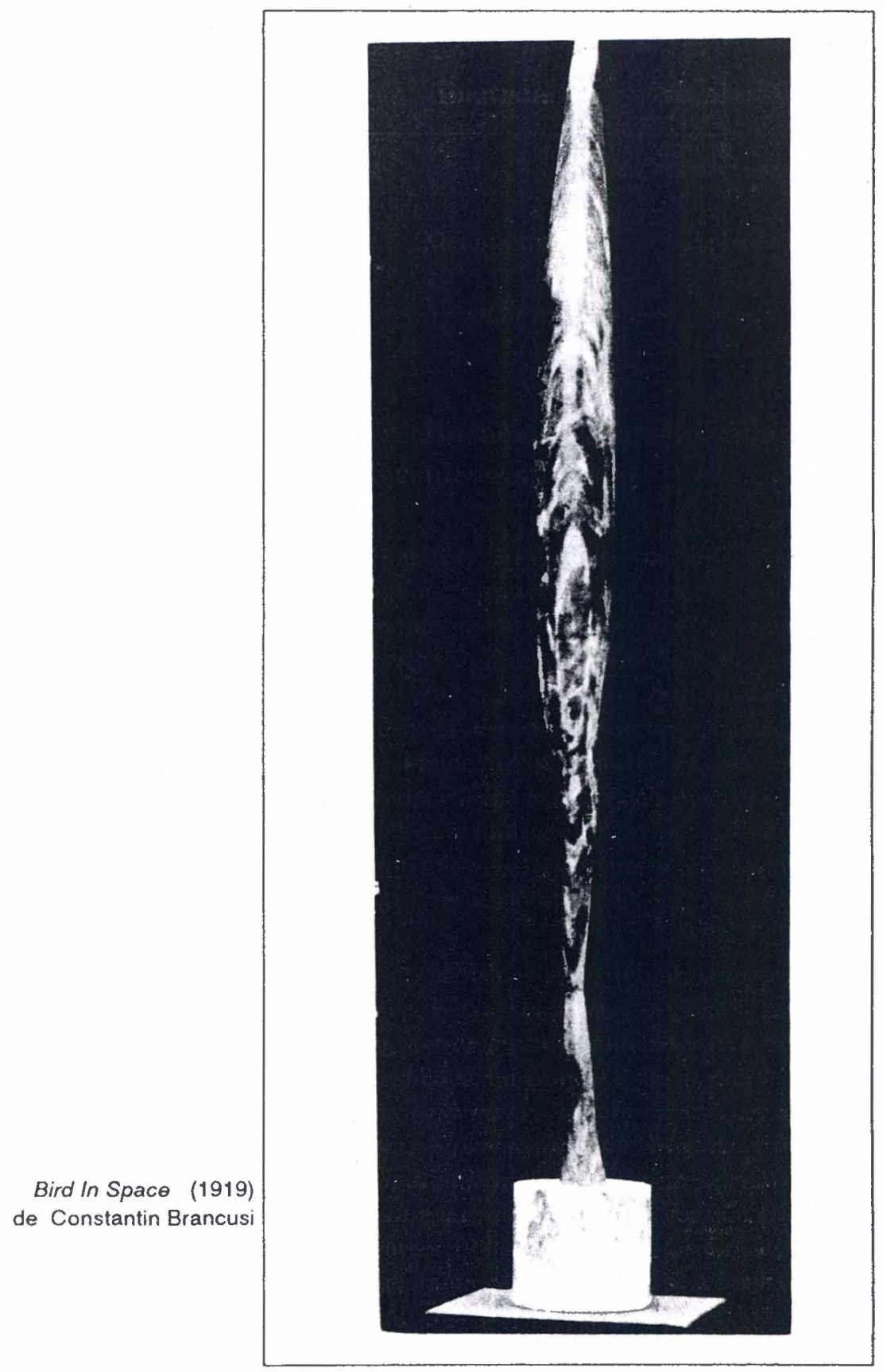


manifesta na superfície discursiva, onde provoca o efeito de sentido de aproximação do real, de iconização, em direção ao não-figurativo, ou mais precisamente, à figuratividade. Uma caminhada que vai desreferencializando o discurso para provocar o efeito de sentido de desreferenciação do signo em relação ao objeto representado. O que vemos é um suprimir, um tirar ou, como gostam de dizer os semioticistas, uma evacuação do sentido. Para quê?

Para tornar cada vez mais cheio. Como? Com o quê?

Desreferenciando o sígnico, desadensando-o para aumentar a incidência do simbólico.

Picasso queria "o mais real do que o real" e produziu "pinturas que parecem não ter nada, mas têm tudo". René Passeron, comentando a desconstrução construtivista da arte cubista, diz que ela está marcada por "uma vontade de infrassistema" (1970: 161 e 162).

O árduo trabalho de (re)invenção da pintura empreendido pelo poetapintor Henri Michaux quer chegar a "formações insignificantes", a signos destituídos de passado e de sentidos prévios. O coroamento de todo esse esforço é "um magro grafismo informe, sem outra espessura que a de uma linha esticada em direção a nada, uma pequena célula de agitação e sobressalto" (Max Loreau, 1980: 39). O resultado dessa desmontagem do sígnico é o seu "homme-en-fil", homem-barbante, homem-linha. "Que não é nada. Sem significação, nem forma, é estranho aos objetos, está aquém do conceito". (Cf. Loreau: 1980: 40). Mas é como tal que ele é bemo signo mínimo de que Michaux precisa: sendo algo completamente diferente de uma imagem ou de uma representação, é esse homem-linha que é guindado por Michaux à condição de um "eu" produror de espaço: "Desde 1942, o homem-linha surge como o núcleo emissor do espaço em torno do qual tudo acontecerá. Homem tênue, de reduzida aparência, encolhido ao extremo, que se resume a quase nada para subtrair-se ao Outro e que, esvaziando, se faz eu - em tudo e por tudo, um vivo jato de energia; [...] o grau mais elementar de existência no mundo, o irredutivel nada que é tudo o que resta em mim quando o Outro foi expulso (Loreau: 1980: 39). É dele que se valerá Michaux como um elemento capaz de produzir o mundo: "à força de secretar e mimar o espaço mais elementar, aquilo que, de início, não era senão energia vazia - nada - acaba sendo o ligamento universal" (Loreau, 1980: 40). 
É curioso! Este homem-linha tão perto de nós, que tão bem nos resume, lembra um outro homem tão longe de nós no tempo: aquele que traça a linha, o rei indo-europeu evocado por Benveniste: ambos põem em jogo forças que, transformando a aparência em sua origem, fazem surgir o espaço. Executam um fazer mágico que recorta, um a tela, outro a terra, inaugurando, nesse gesto radical, a emergência do mundo do sentido.

\section{NOTAS:}

$\left(1^{\circ}\right)$ Insistimos nos exemplos de elaboração lingüística comentados por Cassirer, porque vemos ai um bom ponto de partida para entender o processo de elaboração da metáfora mítica que atua nos momentos mais marcantes da produção plástica moderna. É o que, a nosso ver, acontece com o Pássaro no espaço de Constantin Brancusi (Museu de Arte Moderna de Nova Iorque): numa caminhada sob vários aspectos semclhante à de Picasso, ele chega a uma concepção escultórica extremamente despojada que também isola no pássaro o "momento do vôo" como decisivo e essencial.

$\left(2^{\circ}\right)$ "O mundo natural, da mesma forma que as línguas naturais, näo deve ser considerado como uma semiótica particular, mas antes como lugar de elaboração e de exercicio de múltiplas semióticas. Quando muito, supondo-se a existência de um certo número de propriedades comuns a todas essas semióticas, poder-se-ia tratá-las como uma macrossemiótica" (Greimas, s/d: 292). Nesse mesmo verbete, os Autores esclarecem que o qualificativo natural, empregado para sublinhar o paralelismo do mundo natural com as línguas naturais, serve para acentuar que o indíviduo se integra progressivamente pela aprendizagem - num mundo significante feito ao mesmo tempo de "natureza" e de "cultura". A natureza nãoé um referente neutro, mas fortemente culturalizado (Cf. Grcimas e Courtés, s/d: 291).

\section{TRABALHOS CITADOS:}

1- BENVENISTE, Ė. (1969) - Le vocabulaire des instituitions indocuro curopé́nnes. Paris: Ed. de Minuit.

2- CASSIRER, E. (1945) - Antropología filosófica. Trad. do alemão. México: F.C.E.

3- CASSIRER, E. (1972) - Linguagem e mito. Trad. do alemão. Sāo Paulo: Perspectiva. 
4- GREIMAS, A.J. (1966) - Sémantique structurale. Paris: Larousse.

5- GREIMAS \& COURTÉS (s/d) - Dicionário de semiótica. Trad. Sâo Paulo: Cultrix (A edição é de 1979).

6- GREIMAS \& COURTÉS (Coord.) (1986) - Sémiotiquc. Dictionnaire raisonné de la théorie du langage. Tome 2. Paris: Hachette.

7- KAFKA, F. (1976) - A metamorfose. Trad. do alemão. São Paulo: Clube do Livro.

8- LOREAU, Max (1980) - 'La poésie, la peinture et le fondement du langage (H. Michaux)', in: Loreau, M. (1980) - La peinture à l'oeuvre et l'énigme du corps. Paris: Gallimard

9- OVIDE - Les métamorphoses. Texte établi et traduit par G. Lafaye. Paris: Les Belles Lettres, 1957.

10- PASSERON, R. (1970) - L'Oeuvre picturale et les fonctions de l'apparence. Paris: Vrin.

11 - PICASSO, número especial do CORREIODA UNESCO. Fevereiro de 1981.

12- SCEGELOV, Ju. (1962) - 'Alcunitrattistrutturali delle Metamorfosi di Ovidio', in: FACCANI, R. \& ECO, U. (1969) - I sistemi di segni e lo strutturalismo sovietico. Trad. Milăo: Bompiani. 